\title{
A PORNOGRAFIA ALÉM DO DIREITO À LIBERDADE DE EXPRESSÃO SEXUAL: PRODUTO DE CONSUMO E INSTRUMENTO DE ALIENAÇÃO A SERVIÇO DA TÉCNICA
}

\section{Silvio Marques Garcia}

\section{RESUMO}

Técnica, conforme descreve Jacques Ellul, modifica o meio ambiente, o tempo e o movimento. A sociedade técnica se caracteriza pela busca por eficiência e produtividade. Isso, contudo, traz consequências para o ser humano, deixando-o alienado em relação a questões como ética, responsabilidade e modo de vida. $\mathrm{O}$ vertiginoso desenvolvimento tecnológico experimentado nos últimos anos com a explosão da internet, da imagem digital veiculada pelo DVD, pelos canais de televisão via satélite e pela ampla utilização dos aparelhos de telefonia celular com funções multimídia contribuiu para a expansão da pornografia, a qual, todavia, suscita questões importantes como a exposição da sexualidade, a liberdade de escolha e os direitos humanos. Esse breve estudo pretende demonstrar que, na sociedade técnica, a pornografia, em vez de ser manifestação da 
liberdade de expressão, é utilizada como elemento de alienação do ser humano.

Palavras-chave: Sociedade técnica, internet, pornografia, direitos humanos.

\section{INTRODUÇÃO}

A pornografia na sociedade técnica é utilizada como produto de consumo e elemento de alienação. Busca-se, neste texto, enfocar esse tema a partir dos estudos de Jacques Ellul a respeito da sociedade técnica. Os fundamentos da pesquisa estão contidos na obra A técnica e o desafio do século, assim como outros trabalhos do filósofo francês, e também as exposições do Prof. Jorge Barrientos-Parra no curso de mestrado em Direito do Programa de Pós-Graduação em Direito da UNESP.

Jacques Ellul tem uma visão particular e original sobre a técnica. Ele contesta a identificação entre máquina e técnica, a qual inclui diversas atividades realizadas pelo homem sem relação direta com qualquer tipo de máquina, tais como: o lazer, o entretenimento, o divertimento e o prazer, inclusive a pornografia. Na sociedade industrial, a técnica é uma exigência de racionalidade e se utiliza da pornografia como instrumento de alienação com o intuito de proporcionar seu autocrescimento. ${ }^{428}$

Por outro lado, o tema pornografia traz à tona temas polêmicos ligados aos direitos humanos, tais como: o direito à livre expressão da sexualidade, além de outras questões, como saber se há um limite para as maneiras pelas quais é possível demonstrar essa sexualidade em público.

\section{A ALIENAÇÃO E A PASSAGEM DA SOCIEDADE CAPITALISTA À SOCIEDADE TÉCNICA}

A palavra alienação, do verbo alienar, deriva do pronome latino alienus, que quer dizer outro, alheio. A alienação, na concepção de Paul

\footnotetext{
${ }^{428}$ ELLUL, Jacques. A técnica e o desafio do século. São Paulo: Paz e Terra, 1968. p. 02 .
} 
Lafargue $^{429}$, significa que, com a transformação do trabalho em mercadoria, o próprio trabalhador se torna uma coisa e perde sua condição humana. Passa a ser, ele também, um produto. No livro $O$ direito à preguiça, Lafargue propõe a preguiça, um pecado capital, como um direito, a fim de derrubar o mito do trabalho como uma virtude exaltada pela religião. Sua crítica é dirigida ao modo de produção capitalista, que se vale da divisão social do trabalho para que o trabalhador não se reconheça como produtor da obra produzida, ocultando a essência humana que poderia subjetivar a obra.

Na divisão social do trabalho, o trabalhador pertence à classe que vende sua força de trabalho a outra, à burguesia. Vendida, ela se torna uma mercadoria. $\mathrm{O}$ trabalho, assim, não realiza a capacidade humana. Em vez disso, cumpre as exigências do capitalismo. Ademais, o produto do trabalho se distancia do trabalhador. O que é produzido se destina a atender às necessidades do capital, pertence a um mercado de consumo inacessível ao trabalhador.

A crítica de Lafargue é que o proletariado não pode consumir os produtos de seu trabalho, pois seu salário não lhes permite acesso a eles. A apropriação da riqueza é, pois, restrita à burguesia, detentora dos meios de produção. A preguiça é elogiada como condição para o desenvolvimento do proletariado.

Em Karl Marx, a ideia de alienação surge nos manuscritos de 1844. No livro $O$ Capital, a alienação aparece, sob o manto do fetichismo da mercancia, como um fenômeno ideológico ocasionado pelas condições de trabalho. A alienação do trabalho é apresentada por Marx ${ }^{430}$ primeiramente na relação entre o trabalhador e o produto do seu trabalho; está presente, ademais, na relação entre o trabalhador e sua própria atividade laborativa.

Conforme observa Óscar Correas, a alienação não consiste em alienar (vender) a mercadoria força de trabalho, mas no fato de que o trabalho se desenvolve em condições nas quais o trabalhador não sabe qual é o seu resultado. Ao imaginar que o resultado de seu trabalho é a

\footnotetext{
${ }^{429}$ LAFARGUE, Paul. O direito à preguiça. 2. ed. Trad. de Teixeira Coelho. São Paulo: Editora Unesp, 2000. p. 105.

${ }^{430}$ MARX, Karl. O capital. 8. ed. São Paulo: Difel, 1982, v. 1.
} 
coisa produzida, não vê que se trata da mais valia, a qual, protegida pelo discurso jurídico, é apropriada pelo capitalista. ${ }^{431}$

Desprovido de qualquer outro bem, a única propriedade que resta ao trabalhador alienar é sua força de trabalho, a qual é entregue como mercadoria em troca de salário. O operário vende seu tempo, compromete-se a não se dedicar ao ócio ou à preguiça. Seu tempo e a possibilidade de ter lazer e prazer são, assim, transformados em mercadoria. Marilena Chaui ressalta que "[o] conceito de tempo de trabalho socialmente necessário significa que o custo de produção de uma mercadoria inclui todos os trabalhos que foram necessários para chegar ao produto final. É o custo social de sua produção". ${ }_{332} \mathrm{O}$ custo final da produção da mercadoria incorpora, portanto, o tempo retirado de todos os trabalhadores envolvidos na sua cadeia produtiva, o qual poderia ser utilizado para seu desenvolvimento pessoal, mas se transforma em instrumento do capital ou, conforme uma leitura atualizada a partir de Jacques Ellul, em instrumento da técnica.

Ressalta Chaui ${ }^{433}$, que a burguesia soube transformar em ganho o que incialmente aparecia como uma perda no processo de produção por meio da criação de necessidades fictícias de consumo para a classe proletária. Assim, inventou o consumo de massa de produtos de baixa qualidade e descartáveis. Essa necessidade fictícia surgiu em razão do estímulo ao consumo de novos produtos, oriundos da indústria da moda e do controle do tempo livre dos trabalhadores, feito por meio das indústrias cultural, do esporte e do turismo, tornando dissimuladas a dominação e a exploração.

$\mathrm{Na}$ sociedade contemporânea, a técnica passou a dominar o próprio modo de produção capitalista. Em 1911, havia sido publicado o livro Os princípios da Administração Científica, de Frederick Winslow Taylor, em que se descreveu como poderia ser vigorosamente aumentada a produtividade por meio da decomposição do trabalho em várias etapas fragmentadas, rigorosamente divididas em processos que melhor aproveitariam o tempo e o movimento. Henry Ford pôs em prática esses princí-

431 CORREAS, Óscar. Fetichismo, alienación y teoria del Estado. In: Revista Crítica Jurídica, Curitiba, n. 17, p. 71-81, ago. 2000. p. 75.

${ }^{432}$ CHAUI, Marilena. Introdução à obra $\mathbf{O}$ direito à preguiça. In: LAFARGUE, Paul. $\mathbf{O}$ direito à preguiça. 2. ed. Trad. de Teixeira Coelho. São Paulo: Editora Unesp, 2000. p. 40 .

${ }^{433}$ Idem. p. 48-49. 
pios e deu início à produção de automóveis em grande quantidade e a baixo custo mediante a utilização de linha de montagem.

Em relação ao fordismo, David Harvey ${ }^{434}$ explica que as inovações tecnológicas e organizacionais eram, em diversos aspectos, tendências já consolidadas. O modo de organização dos negócios, por exemplo, já tinha sido aperfeiçoado pelas estradas de ferro durante o século XIX. Havia ocorrido, no final do século, uma onda de fusões, trustes e cartéis em vários setores industriais. $\mathrm{O}$ que Ford fez, com empenho e habilidade, foi adaptar tecnologias já existentes e uma detalhada divisão do trabalho para obter ganhos elevados de produtividade e lucro. A visão de Ford reconhecia que

produção de massa significava consumo de massa, um novo sistema de reprodução da força de trabalho, uma nova política de controle e gerência do trabalho, uma nova estética e uma nova psicologia, em suma, um novo tipo de sociedade democrática, racionalizada, modernista e populista. ${ }^{435}$

O crescimento da produtividade deveria ser acompanhado também pelo do consumo, a fim de possibilitar um aumento ainda maior dos lucros. Exigiam-se investimentos de capital e em marketing, melhorias na administração, a padronização dos produtos e também dos anseios pelo consumo desses novos produtos. Para Henry Ford, poderia ser construído um novo tipo de sociedade:

O propósito do dia de oito horas e cinco dólares só em parte era obrigar o trabalhador a adquirir a disciplina necessária à operação do sistema de linha de montagem de alta produtividade. Era também dar aos trabalhadores renda e tempo de lazer suficientes para que consumissem os produtos produzidos em massa que as corporações estavam por fabricar em quantidades cada vez maiores. ${ }^{436}$

\footnotetext{
${ }^{434}$ HARVEY, David. Condição pós-moderna. 11. ed. São Paulo: Loyola, 2002. p. 102. ${ }^{435}$ HARVEY, David. Condição pós-moderna. 11. ed. São Paulo: Loyola, 2002. p. 122. ${ }^{436}$ Idem. 123.
} 
O fordismo contribuiu, assim, para a busca da funcionalidade e da eficiência ${ }^{437}$ e exaltou os benefícios da produção e do consumo de massa. Os novos métodos de trabalho faziam parte de um novo modo de viver e de pensar, que trazia consigo uma nova moral, a partir das transformações sociais, com consequências sobre várias questões como o consumo, a atuação do Estado, a família e também a sexualidade.

O fordismo ajudou a transformar o proletariado em consumidor dos produtos oferecidos pela sociedade técnica. Anunciou-se o tempo da sociedade industrial e da hegemonia da técnica, um tempo em que o indivíduo é totalmente esvaziado pela técnica em suas várias dimensões, como a do trabalho, a cultural e até mesmo a sexual. Quando não está produzindo, está consumindo. A reformulação do modo de atuação dos trabalhadores para adaptá-los a um sistema de linha de montagem, com a criação de uma rotina de trabalho, encontrou seu paralelo também em outros aspectos da vida, inclusive quanto ao sexo. A partir dessa ideia relativa à padronização do comportamento, pode-se falar em um fordismo sexual.

Freud analisa o princípio ou essência do ser como Eros, em contraste com o tradicional entendimento do ser como Logos. Sabe-se, a partir de Freud, que todo consumo, e o prazer que por meio dele se procura, tem um fundamento libidinoso. Marcuse (1998, p. 94 et seq.) faz uma releitura do marxismo a partir das ideias de Freud, afirmando que Eros redefine a razão a partir de sua busca pela satisfação. Há, para ele, na sociedade moderna, uma alienação erótica crescente. Assim como ocorre com o processo de trabalho, no qual o trabalhador não tem o controle sobre aquilo que faz, fragmenta-se o lazer e a sexualidade em especialidades. O corpo fixa assexuado e o prazer é reduzido ao cumprimento da função de procriar. A repressão à sexualidade faz com que a técnica possa controlá-la a serviço do consumo das novas tecnologias à disposição do mercado. Para isso, surgiram motéis, casas de prostituição, cinemas e uma infinidade de produtos eróticos e pornográficos.

Em $O$ homem unidimensional, Marcuse aponta que a técnica e a ciência, como uma espiral crescente ilimitada, destrói o espírito crítico humano, em vez de permitir a libertação dos trabalhadores de meios de produção. A sociedade capitalista provoca alienação pela manipulação da consciência pela mídia e pela educação de massa. Uma vez desaparecido 
o pensamento crítico, a sociedade não passa de um espaço fechado unidimensional. ${ }^{438}$

Na sociedade industrial, a técnica deixa de ser instrumento de compreensão e desenvolvimento a serviço do ser humano para se tornar instrumento de deturpação da realidade e de dominação das suas atividades. A técnica é a criação de um sistema artificial em que se exclui a espontaneidade e se reduzem fatos e fenômenos a um esquema lógico. Em uma sociedade técnica, o progresso não possui limites. A técnica se reproduz a si mesma, a despeito da intenção humana.

A técnica, para Ellul ${ }^{439}$, é a totalidade de métodos racionalmente utilizados para se obter a eficiência absoluta em todos os aspectos da atividade humana. Representa um modo de vida caracterizado pela fragmentariedade que impede uma visão global, de modo que a eficiência, em última análise, direciona as decisões em detrimento da ética. A técnica se caracteriza pela preocupação, em todos os domínios, de encontrar o melhor caminho, substituir o que era experimental, inconsciente e espontâneo por um modo de fazer consciente em busca da eficiência ${ }^{440}$. As características da técnica contemporânea, segundo Ellul, são: automatismo, autocrescimento, indivisibilidade, universalismo e autonomia. A técnica apresenta um movimento próprio rumo à perfeição, que não pode ser freado. Desenvolve-se, cada vez mais, sem necessidade da intervenção humana.

O indivíduo, em vez de se sentir incomodado por fazer algo mecânico, repetitivo, passa a sentir-se peça importante da técnica. A participação do homem na técnica se dá como se ele fosse uma coisa. Apesar de a técnica tornar o homem aparentemente livre para buscar o que lhe convier, a alienação por ela provocada o faz desejar coisas que aparentemente lhe trariam certa felicidade, a qual jamais será atingida. A técnica neutraliza o subjetivismo do ser humano e tem como uma de suas características marcantes a autonomia. $\mathrm{O}$ indivíduo deixa de ser um agente de escolhas para se transformar em intermediário entre técnicas. Na sociedade atual, a técnica deixou de ser atividade dirigida a valores não técnicos, como a moral, a ética, a religião, a estética etc., para se tornar uma preo-

\footnotetext{
${ }^{438}$ MARCUSE, Herbert. O homem unidimensional: a ideologia da sociedade industrial. Rio de Janeiro: Zahar, 1982. p. 147.

${ }^{439}$ ELLUL, Jacques. A técnica e o desafio do século. São Paulo: Paz e Terra, 1968. p. 408.

${ }^{440}$ Idem. p. 18.
} 
cupação pela eficácia sem qualquer outro conteúdo. Nessa medida, a técnica é sacrílega, como afirma Ellul. ${ }^{441}$

Por isso, pode-se afirmar, com Ellul, que a técnica e não a burguesia ou o capital, além de controlar o tempo gasto com o trabalho, passou a controlar também o tempo de descanso ou livre dos trabalhadores. Tempo segmentado, padronizado, subdividido em rotinas, burocratizado, massificado, comercializado, dispendido com o sexo, enfim, como um produto. Passou, então, a técnica a utilizar estratégias de marketing para provocar nos consumidores o anseio por novos produtos ligados à sexualidade, tornando obsoletas as formas sexuais anteriores.

A sociedade capitalista antecedeu à sociedade técnica. Nessa, a técnica substitui o capital. A técnica modifica o meio ambiente em que o ser humano vive. Hoje, o homem é essencialmente econômico: deve atingir os objetivos, ser eficiente. A busca por altos rendimentos é constante. Em uma época em que se fala de crises econômicas nos principais mercados mundiais, aponta-se, como solução, o consumo.

O acréscimo de novas técnicas é uma característica da época atual e elas se tornam cada vez mais automáticas e mecânicas. A técnica gera uma demanda de novas técnicas, originando um ciclo em que o ser humano fica subjugado à sua voracidade. O progresso técnico torna-se algo irresistível. ${ }^{442} \mathrm{O}$ ser humano deve dar o máximo de si na busca de objetivos que sempre estão à frente das suas possibilidades. Ele caminha cegamente pelos rumos traçados pela técnica em busca de uma perfeição e produtividade que têm como recompensa a promessa de uma felicidade vazia de sentido, que jamais é alcançada.

Verifica-se, portanto, que o ócio, a diversão, o lazer e, enfim, o sexo podem ser transformados em mercadoria, tanto de forma direta, quando oferecidos à fruição em troca de um preço, como de forma indireta ,quando não utilizados em prol dos potenciais titulares.

\section{SEXO, PORNOGRAFIA E INDÚSTRIA CULTURAL}

\footnotetext{
${ }^{441}$ Idem. p. 46.

${ }^{442}$ COSTA, Álvaro Mayrink da. Criminologia. 4. ed. Rio de Janeiro: Forense, 2005.. p. 452.
} 
O sexo foi uma das mais bem-sucedidas invenções da natureza. A criação dos gêneros masculino e feminino permitiu a especialização das tarefas dos indivíduos na procriação das espécies. No caso do ser humano, a gestação foi incumbida à fêmea e, assim, o macho pôde se dedicar à procura de alimentos com maior probabilidade de êxito.

O humano é um ser afetivo e o sexo, com a evolução da humanidade, incorporou-se à cultura como etapa máxima da afetividade, caracterizando uma relação que recebeu a aprovação social e a tutela da religião e, mais tarde, do direito: o casamento. Entretanto, o sexo nunca esteve circunscrito a essa instituição. É frequente, na história, a alusão a episódios em que foi realizado fora do casamento.

A palavra pornografia deriva do grego porne (prostituta) e graphos (escrita) e, originariamente, significava a descrição gráfica sobre prostitutas ou prostituição. Aurélio Buarque de Holanda Ferreira ${ }^{443}$ explica que pornografia se refere a "[figura(s), fotografia(s), filme(s), espetáculo(s), obra literária ou de arte, etc., relativos a, ou que tratem de assuntos obscenos ou libidinosos, capazes de motivar ou explorar o lado sexual do indivíduo."

No grego, a palavra porne era utilizada para referir-se à classe mais baixa das prostitutas, desprovidas de qualquer proteção ou consideração. ${ }^{444}$ Posteriormente, pornografia foi o termo utilizado para referir-se a representação da sexualidade, principalmente a partir da sua utilização pela indústria cultural, englobando tudo que era erótico ou a descrição do corpo nu e também do ato sexual.

Atualmente, a palavra pornografia não se limita à escrita sobre o que é erótico, à descrição dos corpos nus ou do sexo. Por trás do eufemismo está a descrição de situações degradantes para homens e mulheres.

A descrição da pornografia de maneira que afronte o pudor de forma torpe leva à palavra obsceno, que vem do latim obs (a causa de) e coeum (lodo, do grego koinón), a qual indica algo que ofende o pudor

\footnotetext{
443 FERREIRA, Aurélio Buarque de Holanda. Novo dicionário da língua portuguesa. Rio de Janeiro: Nova Fronteira, 1986. p. 1117.

444 KINSELLA, Tina. The banal and the evident: pornography, technology and the market. Journal of Postgraduate Research. Dublin: Trinity College, 2009. Disponível em: http://ncad.academia.edu/TinaKinsella/Papers/762418/The_Banal_and_the_Evident_Porn ography_Technology_and_the_Market. Acesso em: 28.09.2011.p. 2.
} 
causando asco e repugnância ${ }^{445}$. O direito penal tutela a moralidade sexual, prevendo punição para o ato obsceno (art. 233 do Código Penal).

Com o desenvolvimento da cultura, começaram a surgir escritos eróticos que distribuídos a uma plateia seleta, descreviam as mais diferentes manifestações como forma de diversão e obtenção de prazer. Na história da literatura, é comum encontrarem-se referência ao sexo ou à descrição do erótico em diversas obras. Henry Miller, escritor norte-americano, em meados do século XX, teve romances banidos de diversos países por terem sido considerados de conteúdo pornográfico. Hoje em dia, há milhares de blogs na internet que se dedicam à difusão de contos e outros escritos eróticos.

\subsection{A pornografia a serviço da indústria cultural}

Embora seja algo natural, o sexo divorciou-se totalmente do amor e a pornografia tornou-se uma questão industrial. A relação sexual também foi submetida a um processo de industrialização.

No ensaio A obra de arte na era de sua reprodutibilidade técnica, de 1935, Walter Benjamin analisa os impactos promovidos sobre a cultura pelas novas técnicas de produção artística, tais como cinema e a fotografia. Benjamin enfoca as alterações que as obras de arte passaram a sofrer em razão da possibilidade de serem reproduzidas. As técnicas de reprodução acarretaram a superação do caráter aurático da obra de arte, ${ }^{446}$ dando lugar à reprodução em série. Para ele, as obras de arte originais, manualmente produzidas, sempre tiveram o papel de trazem em si um significado ritualístico. Contudo, a partir da reprodutibilidade mecânica, mais independente do que a manual, passou a haver uma distribuição em massa que afastou o caráter aurático da obra de arte.

Segundo Benjamin, a obra de arte, a partir de então, adquiriu um novo papel social, apartando-se da prática idealista da cultura e dando

\footnotetext{
${ }^{445}$ COSTA, Álvaro Mayrink da. Criminologia. 4. ed. Rio de Janeiro: Forense, 2005. p. 454.

${ }^{446}$ A aura referida por Benjamin diz respeito à dependência da obra aos juízos de valor que lhe são atribuídos em seu contexto histórico.
} 
lugar a um conceito materialista da cultura ${ }^{447}$. Estabelece-se, assim, uma nova interação entre o público e a produção artística. Em Benjamim, a técnica fez o erotismo deixar de ser obra de arte, para transformar-se em instrumento de alienação. Benjamim percebeu de forma crítica os perigos da técnica introduzida pela indústria capitalista na cultura, abrindo caminho para as reflexões propostas pela Escola de Frankfurt.

Adorno e Horkheimer, em A indústria cultural: o esclarecimento como mistificação das massas (1947), destacam a industrialização da cultura como uma característica da produção cultural no século XX. De acordo com os citados autores, as técnicas de reprodução, juntamente com os meios de comunicação em massa, possibilitaram a criação de produtos culturais em larga escala. Essa reprodução exige capital e não foi possível que os artistas as realizassem, o que deu origem a uma organização empresarial que transformou a cultura em um produto, submetido à produção industrial. ${ }^{448}$

Essa industrialização expandiu-se e deixou de ser um instrumento de reprodução da cultura, a qual passou a ter menos importância que o próprio mercado. O processo de industrialização tornou-se um condicionante da produção cultural, dando origem a uma explosão de novas técnicas rapidamente incorporadas, como o rádio, a televisão e a internet, sempre com fundamento na intensa utilização de capital e nas regras de mercado.

A industrialização da cultura e a exploração econômica da obra de arte fizeram com que esta renunciasse sua autonomia e, assim, sua função foi transferida para o âmbito do consumo. ${ }^{449}$ A produção da cultura passou a ser orientada pelas regras do mercado. As obras de arte, na indústria cultural, deixam de ser um ambiente de reflexão da cultura para figurar na esfera do consumo, abrindo espaço para um mercado controlado monopolisticamente, como adverte Costa:

447 BENJAMIN, Walter. A obra de arte na era de sua reprodutibilidade técnica. In: Magia e técnica, arte e política: ensaios sobre literatura e história da cultura. São Paulo: Brasiliense, 1994. p. 172.

448 ADORNO, Theodor W.; HORKHEIMER, Max. A indústria cultural: o esclarecimento como mistificação das massas. In: Dialética do esclarecimento: fragmentos filosóficos. Tradução de Guido Antonio de Almeida. Rio de Janeiro: Jorge Zahar Ed., 1985.

${ }^{449}$ Idem. p. 147. 
A indústria sexual está controlada monopolisticamente, enfocando toda a sorte de libertinagem nas praias, nos 'campings', no interior dos cinemas (espetáculos especiais depois das 24 horas), no interior dos veículos, no interior austero dos escritórios, quando não mascarados por atividades 'salutares' (massagens, temas só para homens), anunciados ao grande público pelos meios de comunicação. As grandes festas populares (carnaval) perdem o seu verdadeiro sentido. ${ }^{450}$

É possível afirmar que a técnica apropriou-se da fórmula industrial para a transformação da sociedade técnica. A existência de novos meios técnicos desperta a necessidade de sua utilização. Afinal, tudo é feito em favor da evolução científica, a fim de trazer maior comodidade ao indivíduo. Muito embora, às vezes, a mensagem possa ser desprovida de um conteúdo ético, como ocorre com a pornografia, essa necessidade de utilização dos novos meios técnicos acaba legitimando a mensagem por eles divulgada. A técnica, assim, cria um mercado de consumo e gera uma demanda por mais e mais pornografia, legitimando que seres humanos sejam expostos amarrados, açoitados, violentados e submetidos a formas violentas e bizarras de sexo como se fosse o único meio de saciar seus desejos. ${ }^{451}$

A indústria da pornografia movimenta milhões de dólares e age como qualquer outra que atua no mercado mundial. $\mathrm{O}$ filme clássico do cinema pornô Deep Throat, de 1972, por exemplo, alterou a cultura sexual dos Estados Unidos e arrecadou milhões de dólares ao redor do mundo. Uma vez criado o mercado para o sexo, agora transformado em produto, a pornografia se espalha a serviço da técnica e alarga suas fronteiras, para suprir a necessidade dos consumidores (criada pela própria técnica).

Não são as necessidades humanas que ditam a produção industrial. Ao contrário, o que é necessário ao ser humano é definido pelo mercado.

Assim, o conceito de supérfluo se torna fluido e um produto jamais será supérfluo se a vontade do mercado for a de que deverá ser pro-

${ }^{450}$ COSTA, Álvaro Mayrink da. Criminologia. 4. ed. Rio de Janeiro: Forense, 2005. p. 457

451 DWORKIN, Andrea. Pornography: men possessing woman, 1981, p. 327, apud KINSELLA, 2009. p. 3. 
duzido e consumido. A técnica se utiliza da publicidade para estimular seu autocrescimento. Como afirma Daiene Garcia ${ }^{452}$, a técnica se aproveita da dificuldade de o consumidor, alienado, perceber a nocividade do conteúdo publicitário, por meio da persuasão, fazendo que o indivíduo consuma produtos que cada vez mais tenham a mais recente tecnologia agregada a sua produção. Com a pornografia não é diferente.

\subsection{A disseminação da pornografia como produto}

Transformada em produto, a pornografia se dissemina por meio de novas técnicas. Entretanto, não há um controle humano sobre a velocidade e os meios de divulgação, porque a técnica, ela própria, utiliza-se da pornografia e do mercado de consumo para fomentar o seu autocrescimento.

A atividade sexual descrita na pornografia faz o observador aceitá-la e crer na sua legitimidade. A tecnologia não apenas é um veículo disseminador, mas também cria a pornografia. As imagens e sons com conteúdo pornográfico produzem no expectador uma aquiescência ao seu conteúdo. A necessidade de utilização de novas técnicas legitima a pornografia, que é apenas parte da indústria cultural, em que o consumidor se torna um alvo inerme forçado a aceitar os produtos fornecidos por esse mercado. ${ }^{453}$

A partir do marketing criado para a satisfação da libido, buscase a máxima eficiência sexual. Propõe-se um orgasmo permanente em que o indivíduo deve estar preparado para a cópula a qualquer momento. Inventaram-se medicamentos para a disfunção erétil e a impotência sexual. Especializaram-se os tratamentos e foram criadas lojas dedicadas à venda de produtos eróticos, que estimulam a sexualidade: os sex shops. O ser humano ficou pequeno e limitado demais para o sexo, que para ser

\footnotetext{
452 GARCIA, Daiene Kelly. O pensamento de Jacques Ellul e uso das novas tecnologias na veiculação da publicidade: a alienação como instrumento da técnica. In: Anais do IV Seminário Brasileiro sobre o pensamento de Jacques Ellul: Os desafios da técnica no século XXI: direitos, propaganda e política. Araraquara: Faculdade de Ciências e Letras, Universidade Estadual Paulista, 2011, p. 95.

453 DWORKIN, Andrea. Pornography: men possessing woman, 1981, p. 327, apud KINSELLA, 2009. p. 2.
} 
considerado divertido deve ser cada vez mais apimentado com o uso de uma série de petrechos desenvolvidos para essa finalidade.

O homem e a mulher foram transformados em máquinas sexuais. Seus corpos foram transformados por meio de procedimentos desenvolvidos pela medicina: os implantes de silicone, o rejuvenescimento, o emagrecimento e o ganho de formas esculturais. A quantidade de cirurgias plásticas é espantosa, principalmente no Brasil. ${ }^{454}$ A noção de beleza está cada vez mais ligada à satisfação sexual. Se não se atinge o orgasmo, deve-se fingi-lo, para satisfazer o parceiro. Pílulas produzidas para solucionar problemas de disfunção erétil passaram a ser utilizadas por homens sadios com a finalidade de prolongar o prazer por horas. Esse comportamento é estimulado por simulações de relações sexuais que são fotografadas ou gravadas, editadas e apresentadas ao público como forma de entretenimento: as revistas e os filmes pornográficos.

Atualmente, o sexo está em tudo. Está nas bancas de revistas, no cinema, no teatro, na televisão, na música etc. $\mathrm{O}$ assunto sexo é muito lucrativo. Arrecadam-se milhões com a venda de produtos relacionados à sexualidade. A possibilidade de exploração financeira da pornografia como produto ensejou a criação de várias empresas especializadas na produção industrial de material pornográfico destinado a um grande segmento de consumidores, tornando-a uma rentável área do mercado. Exemplo disso é a rede de televisão norte-americana Playboy $T V$, originada da revista erótica de mesmo nome, que possui uma programação inteiramente focada na pornografia. A televisão, no entanto, possibilitou a criação de programas em que o sexo é apresentado de forma cada vez mais ostensiva.

A sexualidade está presente atualmente nos mais diversos gêneros a que se dedica o cinema, desde filmes especificamente produzidos para o mercado pornográfico até filmes criados como obras artísticas e, como tais, premiadas e aclamadas pelo público.

Na televisão, poucos anos se passaram entre o primeiro beijo e a primeira relação sexual explícita. Hoje, o sexo é assunto predileto das novelas e seriados de TV com maior audiência, como o norte-americano

${ }^{454}$ De acordo com o site Abril.com, foram realizadas no Brasil, entre setembro de 2007 e agosto de 2008, 1.252 operações estéticas por dia. (Agência Estado, Brasil registra 1,2 mil cirurgias plásticas ao dia, Disponível em: <http://www.abril.com.br/noticias/brasil/brasil-registra-1-2-mil-cirurgiasplasticas-ao-dia-268017.shtml>. Acessado em: 13.12.2011.) 
Two and a half man e as novelas nacionais. Aliás, dada à projeção de audiência que o assunto enseja, a Rede Globo chegou a dedicar ao tema um programa específico, denominado Amor e Sexo.

Na música, o sexo foi sendo tratado cada vez com mais frequência e profundidade. Há algumas décadas, as músicas nacionais falavam predominantemente de amor, permitindo-se umas poucas concessões para a palavra sexo, que aos poucos penetrou nessa seara artística por meio de eufemismos como "fazer amor". No Carnaval, as marchinhas faziam concessões ao preconceito, referindo-se de modo pejorativo a opções diferentes de manifestação sexual, como a homossexualidade (Maria Sapatão e Cabeleira do Zezé) e também ao preconceito racial, permitindo a relação com o negro apenas para fins sexuais e rejeitando a união duradoura entre raças diferentes, o que fica evidente na música $O$ teu cabelo não nega.

Um dos exemplos internacionais mais marcantes da pornografia como técnica de alienação na música é a cantora Kate Perry, a primeira mulher a emplacar cinco sucessos no primeiro lugar da parada norteamericana. Suas músicas falam de orgia, sexo a três, sexo casual, relações homossexuais etc. e são tocadas em todas as emissoras e danceterias pops. Também no Brasil, o sexo virou tema central, desde o funk carioca (Tô ficando atoladinha, cantada pelo Mc Bola de Fogo, Dako é bom, da funkeira Tati Quebra-Barraco e as músicas da cantora conhecida como Valeska Popozuda) e o axé baiano ("Ela é toda boa" do grupo Psirico) até a música sertaneja-pop (Fugidinha e o sucesso internacional $\mathrm{Ai}$, se eu te pego! do cantor Michel Teló). Os temas são sutis e fazem o uso de trocadilhos, como sugerem os próprios nomes das canções. Já as coreografias insinuam movimentos que remetem ao ato sexual.

A curiosidade por conhecer a nudez da atriz da novela, da cantora pop, da dançarina de certa banda, da apresentadora de televisão, da participante de algum reality show ou de outra celebridade qualquer garante o sucesso das revistas dirigidas ao público masculino. Entretanto, o feminismo estendeu à mulher os problemas do homem relativos ao sexo. Com a expansão do feminismo e o reconhecimento do direito constitucional de livre manifestação do pensamento, as mulheres e os homossexuais, antes reprimidos em relação a manifestar sua sexualidade, passaram a ser o público-alvo de revistas específicas com conteúdo erótico.

$\mathrm{O}$ ser humano busca ter acesso a certa qualidade de vida que the possibilite a comodidade e o prazer. É induzido, por toda parte, a compor- 
tar-se de determinado modo, como se sua felicidade dependesse disso. No entanto, trabalha sem trégua em busca de algo que nem sempre é necessário para sua vida. Além disso, o prazer anunciado com a pornografia, ao não ser alcançado, promove uma busca por modalidades cada vez mais bizarras de sexo, podendo até mesmo chegar à violência como parte da satisfação. O sexo, assim, como o próprio sentido da vida, foi reduzido ao consumo.

\section{DIREITOS FUNDAMENTAIS E VIOLAÇÃO À LIBERDADE SEXUAL}

A mercantilização do sexo, por meio da pornografia, é questão polêmica que se relaciona aos direitos fundamentais. Há um aparente conflito entre direitos: de um lado, o direito à livre manifestação do pensamento e da liberdade sexual de alguns cidadãos e, de outro, o direito à intimidade e à integridade de outros. A pornografia não se restringiu a um mercado selecionado de poucos expectadores, como antigamente. Espalhou-se para todos os meios de comunicação, sem restrições, chegando a todas as casas às vezes de modo a afrontar os direitos de muitas pessoas.

Por essa razão, questiona-se atualmente a possibilidade (legalidade) de se utilizar, por exemplo, a mulher como mero objeto passivo do ato sexual. Até hoje, a mulher ainda é vista como instrumento do prazer masculino e, por vezes, é colocada pela mídia em situação considerada discriminatória por grupos de feministas. Por isso, até mesmo na propaganda de cervejas, busca-se a igualdade de direitos, e as mulheres já aparecem como consumidoras que são, desaparecendo aos poucos aquele papel de simples beldades postas ao desfrute sexual masculino. Percebese que a violação de direitos, na sociedade técnica, ocorre das formas mais sutis, tudo em nome da ambição da técnica pela autorreprodução e automatismo.

Outro fenômeno ligado aos direitos humanos atualmente em questão é a existência de violação dos direitos das mulheres em um âmbito jamais visto na história das guerras (Como ocorreu no Congo e em desastres humanitários recentes). Além disso, nesses episódios, têm sido violados também os direitos dos homens à liberdade sexual.

Cumpre perguntar se é possível afirmar que atingimos um paroxismo em matéria de pornografia. Quais serão os próximos limites da 
utilização da pornografia pela técnica para a alienação do ser humano? As novelas já mostram relações sexuais, beijos exageradamente eróticos, relações thressome. $\mathrm{O}$ que mais falta em relação à sexualidade para ser exibida e dela tirado proveito em prol de objetivos completamente desprovidos de conteúdo axiológico?

Em muitos aspectos, a pornografia foi o motor da técnica e proporcionou a evolução de vários tipos de equipamentos, como os videoteipes, a fotografia instantânea, a internet etc. ${ }^{455}$ De outro lado, quando surgem novos veículos de mídia, rapidamente a pornografia deles toma conta e os manipula. Vários foram os equipamentos desenvolvidos para a indústria da pornografia. Certos projetores cinematográficos e outros se popularizaram com a pornografia como a câmera fotográfica da Polaroid que tirava fotografias e as revelava instantaneamente, o que evitava ter de levar o filme até um laboratório de revelação. Isso ocorre atualmente com os aparelhos de telefonia celular, a grande maioria equipada com câmeras, frequentemente utilizadas para a captura de cenas com conteúdo pornográfico, as quais, com o término do relacionamento, não raro caem na rede mundial de computadores, acarretando mais uma forma de violação da intimidade. Algumas tecnologias, desde o aparecimento do VHS até o Blue Ray, têm sua criação, aplicação inicial ou popularização relacionadas à pornografia. Exemplo disso é a tecnologia de TV a cabo e o sistema pay-per-view, que possibilitaram a entrega de material pornográfico na residência do consumidor sem a necessidade de intermediários ou dissimulação. ${ }^{456}$

Como mencionado acima, a técnica modifica o tempo e o movimento. $\mathrm{O}$ ser humano dedica-se em tempo integral a atividades que lhe possam fornecer o dinheiro necessário para garantir sua felicidade. Com isso, não tem tempo para se entregar a relacionamentos com seres humanos reais. Cresce, assim, a popularidade do sexo na internet e as relações virtuais. A popularidade desse tipo de conteúdo é tamanha que recentemente surgiram sites especializados em possibilitar encontros de pessoas casadas, estimulando traições virtuais e reais.

Visitando-se qualquer site de busca da internet, é possível verificar que há uma infinidade de páginas com conteúdo pornográfico. A era da informação ampliou os horizontes do conhecimento humano, franque-

455 MATYSZCZYK, Chris. So porn revolutionizes technology, right? Disponível em: http://news.cnet.com/8301-17852_3-10290322-71.html. Acesso em: 29.09.2011.

${ }^{456}$ Ibidem . 
ando-o a todas as camadas e o expandindo além dos muros das bibliotecas e das escolas. Não obstante, a quantidade de pornografia existente na rede mundial de computadores impressiona. Talvez seja maior do que conteúdo não pornográfico.

A internet trouxe uma colaboração à técnica especificando ainda mais as categorias pornográficas. As páginas propõem a exibição da pornografia por meio de categorias e subcategorias cada vez mais específicas, distribuídas por idades, raças, opção sexual e grau de aprimoramento da pornografia (fetiche, hardcore, tools, bissexual threesome, sexgroup, lesbian, gay, bizzarre etc.) Não é possível prever quais os limites da discriminação a direitos quanto à sexualidade e aos exageros das exibições ligadas ao sexo.

A sociedade atual reconhece o direito de cada pessoa à opção sexual. A jurisprudência do Supremo Tribunal Federal reconheceu a união homoafetiva como entidade familiar. Garantiu também a liberdade de manifestação do pensamento. Todavia, é necessário pôr em discussão os limites da pornografia e a sua utilização como instrumento de alienação. A exibição ilimitada do sexo poderá levar à busca da felicidade por outros caminhos, como o da violência sexual, que vem aumentando cada vez mais. Por isso, quando se fala em pornografia, não se pode limitá-la a determinados grupos, como as prostitutas e os homossexuais, como se fossem os seus causadores, pois, na maioria das vezes, tornam-se vítimas da violência que, ainda que indiretamente, ela estimula.

A banalização do sexo tem seu lado positivo, qual seja, o de quebrar antigos tabus arraigados na sociedade segundo os quais a mera alusão ao órgão sexual ou a qualquer coisa a ele ligado era motivo de risos. A pornografia contribui, assim, para a plasticidade do meio social, na medida em que ajuda a quebrar tabus presentes nas estruturas sociais vigentes.

As novas tecnologias, especialmente as mídias sociais, possuem como característica a ambivalência: trazem uma contribuição para a educação, mas também tem efeitos deletérios. Neil Postman ${ }^{457}$ estudou a conexão entre mídia e educação, especialmente as consequências da televisão e de outros meios de comunicação de massas sobre as crianças. Para ele, as crianças são submetidas a uma erotização precoce que derruba as fronteiras entre os mundos adulto e infantil. Na televisão, a descrição da

457 POSTMAN, Neil. O desaparecimento da infância. Trad. Suzana Menescal de A. Carvalho e José Laurenio de Melo. Rio de Janeiro: Grafhia Editorial, 1999. 
infância é posta de lado, as brincadeiras infantis foram esquecidas. De outro lado, o mundo dos jovens tem se aproximado do dos adultos, influenciando, principalmente a linguagem. Para Postman, a erotização das crianças e participação crescente de jovens na criminalidade são aspectos que demonstram que a infância está desaparecendo. O problema, para ele, é que a discussão atual sobre as novas tecnologias se restringe às vantagens e não há ênfase sobre as desvantagens.

Ressalta Costa, que "[não há possiblidade de criar-se uma teoria objetiva do pornográfico, razão pela qual, se não fixarmos como ponto de partida o propósito sexual predominante, torna-se impossível discernir entre o pornográfico e o artístico". ${ }^{458}$ A pornografia, no entanto, deve ter limites. Todos sabem e saberão, no momento oportuno, o que é o sexo e para que serve, pois é algo instintivo. É preciso analisar os direitos em conflito, optando-se por resguardar a existência de uma sociedade livre de violência e preconceito, inclusive quanto à manifestação da sexualidade. Contudo, a liberdade não existirá se houver a permissão para comportamentos tendentes a violar outros direitos. Por isso, há a necessidade de controle quanto ao acesso à pornografia. Se de um lado não é possível, numa sociedade democrática, proibi-la, de outro, é preciso fixar limites à sua incidência na televisão, nas emissoras de rádio, na publicidade e, principalmente, na internet, para que o acesso seja restrito. Não se deve permitir que ela, sem barreiras, atinja os cidadãos na televisão, no cinema, na música, na internet, na publicidade, sem que estejam buscando especificamente esse conteúdo. Entretanto, não é o que se vê na sociedade contemporânea. Consoante afirma Daiene Garcia,

[o] conteúdo veiculado pela publicidade por meio da informática e da telemática, assim como ocorre nas demais mídias, deve estar em conformidade com os valores sociais, éticos e morais e apresentar o seu caráter publicitário de modo explícito e fundamentado, evitando-se a publicidade enganosa e (ou) abusiva. ${ }^{459}$

\footnotetext{
${ }^{458}$ COSTA, Álvaro Mayrink da. Criminologia. 4. ed. Rio de Janeiro: Forense, 2005. p. 461.

${ }^{459}$ GARCIA, Daiene Kelly. O pensamento de Jacques Ellul e uso das novas tecnologias na veiculação da publicidade: a alienação como instrumento da técnica. In: Anais do IV
} 
Esse mesmo raciocínio deve ser aplicado em relação à pornografia, evitando-se conteúdos que ultrapassem o limite do artístico e da liberdade de expressão para cair no âmbito do obsceno. A pornografia infantil é o maior exemplo da necessidade de limites para a veiculação de conteúdo pornográfico na mídia. É uma das questões que trazem maior preocupação atualmente, pois são frequentes os relatos de exposição de crianças nuas e de cenas de sexo com crianças na internet. Além de ser crime, tal conduta demonstra uma potencialidade lesiva muito grande, pois essa modalidade de exposição incita a prática de violência contra outras crianças e jovens. Daí a necessária prioridade da atuação do Estado no combate à pornografia infantil. Deve ser lembrada a lição de Ellul no sentido de que a técnica não é dotada de ética. A rede mundial de computadores trouxe novas ferramentas de incentivo à pornografia infantil. Não obstante, a própria técnica tem especial relevância no combate a esse tipo de crime. Cada vez se exige um conhecimento mais aprofundado para a busca de instrumentos de combate aos crimes cibernéticos, dentre eles a pornografia infantil.

Outro problema que pode ilustrar a pornografia como produto de consumo é o turismo sexual. O Brasil é conhecido como um dos destinos do turismo sexual, principalmente as capitais dos Estados do Nordeste. Além disso, muitos são os brasileiros que se sustentam por meio da venda de seus corpos não só aqui, mas também em outros países, sobretudo na Europa, o que acaba gerando outra violação de direitos: o tráfico de seres humanos.

Para que não se arraste demasiado a discussão, basta, em resumo, mencionar que a pornografia diz respeito também ao Direito, pois envolve relações humanas e, como tais, devem ser disciplinadas pelo ordenamento jurídico. Assim, está sujeita à incidência de leis que limitem as suas formas, locais, veículos e horários de divulgação, até situações em que a pornografia é crime (pornografia infantil) ou mesmo imoral (episódios ocorridos com políticos). Não obstante, grande parte das pessoas envolvidas na pornografia a têm como profissão e, assim, devem ter reconhecidos seus direitos trabalhistas e previdenciários. Ironicamente, entretanto, a mesma sociedade consumidora de pornografia resiste à ideia de

Seminário Brasileiro sobre o pensamento de Jacques Ellul: Os desafios da técnica no século XXI: direitos, propaganda e política. Araraquara: Faculdade de Ciências e Letras, Universidade Estadual Paulista, 2011. p. 96. 
reconhecer a dignidade à atividade exercida por prostituas, modelos, atores e outros profissionais do sexo.

Hoje, portanto, o sexo está banalizado e funciona como um instrumento da técnica para obter a alienação do ser humano.

\section{CONSIDERAÇÕES FINAIS}

O sexo é uma função essencial à vida. Com a evolução da humanidade, o ato sexual foi perdendo seus contornos de brutalidade e, amparado pelo senso de pudor, o ser humano passou a ver no sexo uma forma de manifestação do amor. A liberdade de expressão da sexualidade, portanto, tornou-se indispensável para o convívio social e a integração cultural, guiada, não obstante, por uma eticidade na manifestação da sexualidade individual.

Na sociedade contemporânea, além de modificar o meio ambiente, a técnica modifica o tempo e o movimento, de forma que o tempo da sociedade técnica é um tempo dominado pelo relógio. O horário de trabalho ampliou-se. Não se limita às horas que medeiam os marcos fixados nos cartões de ponto. É necessário um comprometimento com a empresa, que exige dedicação integral. A busca por eficiência e produtividade traz consequências no ser humano, deixando-o alienado em relação a questões como ética, responsabilidade e modo de vida. Enquanto modificadora do tempo, a técnica se sobrepõe ao tempo do homem, caracterizado por suas necessidades biológicas. Isso também ocorre em relação ao sexo, que passa a ser objeto de consumo buscado incessantemente e não um estímulo decorrente da natureza biológica humana.

Todavia, a técnica não se submete à ética, à religião, ao direito ou a qualquer outro padrão. Ela busca um aprimoramento cada vez maior e não tem reservas quanto à sua utilização em atividades contrárias à ética, a exemplo das experiências científicas em campos de concentração, das bombas atômicas, da criação de seres mistos de humanos e animais para fins de pesquisa científica e da pornografia infantil na internet.

Como visto, a sexualidade e a pornografia podem ser analisadas a partir das características da técnica apontadas por Jacques Ellul. A pornografia, em nossa sociedade, é um elemento de alienação a serviço da técnica, ao exigir novos tipos de mídias e rapidamente se aproveitar de 
todo tipo de veículo que surge para chegar cada vez mais ao alcance da população, produzindo e reproduzindo os efeitos desejados pela técnica.

Na sociedade técnica, o sexo se transformou em um produto industrial alienante e o mercado, de olho nesse lucrativo nicho, contribuiu para a disseminação e utilização da pornografia como instrumento de alienação.

Apropriada pela técnica, a pornografia se especializou, dando origem a categorias e subcategorias, cada qual destinada a um consumidor específico ou a certo veículo de divulgação. Popularizou-se a tal ponto de deixar de ser objeto de consumo de um público seleto para ingressar nas redes de televisão, no cinema, na música, na internet, nos outdoors e até mesmo na cultura, influenciando, inclusive, a moda.

A pornografia hoje está em todo lugar, não possui fronteiras espaciais ou ideológicas. Disseminou-se. Globalizou-se num mundo globalizado. Pode ser encontrada na televisão, no cinema, na música, em CDs e DVDs, em aparelhos de telefonia celular, em computadores. Acima de tudo a pornografia não tem pátria, permeia a rede mundial de computadores e está virtualizada. Ao espalhar-se pelas diversas e inovadoras mídias, é apontada como precursora na utilização de novos mercados e novas tecnologias, das quais a técnica rapidamente se apropria, utilizando a pornografia como instrumento de alienação.

A expansão da pornografia atingiu as mulheres, com o feminismo, e agora começa a popularizar-se em um público cada vez mais jovem. Embora não se possa deixar de registrar a quebra de certos tabus por ela proporcionada, transformou-se, ao ser apropriada pela técnica, em instrumento desprovido de ética, capaz de difundir a prática de crimes como a pornografia infantil.

Dentre os principais efeitos deletérios causados pela alienação da sexualidade, está a banalização do comportamento em relação ao amor e à ética que deve orientar as relações humanas. O sexo foi perdendo aos poucos seu caráter de manifestação do afeto entre as pessoas, para tornarse um objeto de consumo esvaziado de sentido que, após seu uso, não traz a satisfação que a expectativa de sua prática prometia, exigindo-se, assim, formas cada vez mais bizarras de expressão.

A pornografia chega a tal ponto que também ela gera desenvolvimento tecnológico, tudo para permitir uma aparente satisfação alienante que ajuda a colocar o ser humano cada vez mais a serviço da técnica. Daí a atualidade da obra de Jacques Ellul, que vem despertar o leitor para a 
ausência de qualquer conteúdo axiológico ou outro elemento externo à técnica que possa guiar seu desenvolvimento, bem como para a necessidade de libertar-se da alienação que a técnica produz.

Para superar a técnica, é necessário questionar todas as bases em que se funda nossa sociedade, suas estruturas sociais, políticas e o modo de vida do ser humano. Esse questionamento deve partir do interior de cada indivíduo, de modo a disseminar-se entre os demais e alcançar uma força social tal que possa permitir ao ser humano contemporâneo reverter os distúrbios provocados pela técnica em nossa civilização.

\section{REFERÊNCIAS BIBLIOGRÁFICAS}

ADORNO, Theodor W.; HORKHEIMER, Max. A indústria cultural: o esclarecimento como mistificação das massas. In: Dialética do esclarecimento: fragmentos filosóficos. Tradução de Guido Antonio de Almeida. Rio de Janeiro: Jorge Zahar Ed., 1985.

BARRIENTOS-PARRA, Jorge. A técnica como desafio do século XXI. In: In: Anais do IV Seminário Brasileiro sobre o pensamento de Jacques Ellul: Os desafios da técnica no século XXI: direitos, propaganda e política. Araraquara: Faculdade de Ciências e Letras, Universidade Estadual Paulista, 2011, p. 69-80.

BATTERSBY, Matilda; RILEY, Jack; RICKMAN, Dina. iSex: how pornography has revolutionized technology. Disponível em: $<$ http://independent.co.uk/life-style/gadgets-and-tach/features/isexhow-pornography-has-revolutionized-technology>. Acesso em 28.09.2011.

BENJAMIN, Walter. A obra de arte na era de sua reprodutibilidade técnica. In: Magia e técnica, arte e política: ensaios sobre literatura e história da cultura. São Paulo: Brasiliense, 1994.

CARVALHO, Fabíola de Souza; BARRIENTOS-PARRA, Jorge. A questão do entretenimento na sociedade técnica. Anais do I Seminário Brasileiro sobre o pensamento de Jacques Ellul. Araraquara: UNESP, 2010.

CHAUI, Marilena. Introdução à obra $\mathbf{O}$ direito à preguiça. In: LAFARGUE, Paul. $\mathbf{O}$ direito à preguiça. 2. ed. Trad. de Teixeira Coelho. São Paulo: Editora Unesp, 2000. 
CORREAS, Óscar. Fetichismo, alienación y teoria del Estado. In: Revista Crítica Jurídica, Curitiba, n. 17, p. 71-81, ago. 2000.

COSTA, Álvaro Mayrink da. Criminologia. 4. ed. Rio de Janeiro: Forense, 2005.

DWORKIN, Andrea. Pornography: men possessing woman, 1981, p. 327, apud KINSELLA, 2009.

ELLUL, Jacques. A técnica e o desafio do século. São Paulo: Paz e Terra, 1968.

. The betrayal by technology: a portrait of Jacques Ellul. Disponível em <http://www.youtube.com/watch?v=51IoQOJ0Sf Y\&feature=related $>$. Acesso em: 15.09.2011.

FERREIRA, Aurélio Buarque de Holanda. Novo dicionário da língua portuguesa. Rio de Janeiro: Nova Fronteira, 1986.

FOLEY, John. Technology and the fight against child porn. Disponível em <http://www.informationweek.com/news/60400181>. Acesso em: 29.09.2011.

GARCIA, Daiene Kelly. O pensamento de Jacques Ellul e uso das novas tecnologias na veiculação da publicidade: a alienação como instrumento da técnica. In: Anais do IV Seminário Brasileiro sobre o pensamento de Jacques Ellul: Os desafios da técnica no século XXI: direitos, propaganda e política. Araraquara: Faculdade de Ciências e Letras, Universidade Estadual Paulista.

GARCIA, Silvio Marques. A pornografia como elemento de alienação em nosso tempo: uma abordagem a partir de Jacques Ellul. In: Anais do IV Seminário Brasileiro sobre o pensamento de Jacques Ellul: Os desafios da técnica no século XXI: direitos, propaganda e política. Araraquara: Faculdade de Ciências e Letras, Universidade Estadual Paulista, 2011.

HARVEY, David. Condição pós-moderna. 11. ed. São Paulo: Loyola, 2002.

KINSELLA, Tina. The banal and the evident: pornography, technology and the market. Journal of Postgraduate Research. Dublin: Trinity College, 2009. Disponível em: <http://ncad.academia.edu/TinaKinsella/Papers/762418/The_Banal _and_the_Evident_Pornography_Technology_and_the_Market>. Acesso em: 28.09.2011.

LAFARGUE, Paul. O direito à preguiça. 2. ed. Trad. de Teixeira Coelho. São Paulo: Editora Unesp, 2000. 
MARCUSE, Herbert. Eros and civilization: a philosophical inquiry into Freud. London: Routledge, 1998.

. O homem unidimensional: a ideologia da sociedade industrial. Rio de Janeiro: Zahar, 1982.

MARX, Karl. O capital. 8. ed. São Paulo: Difel, 1982, v. 1.

MATYSZCZYK, Chris. So porn revolutionizes technology, right? Disponível em: <http://news.cnet.com/8301-17852_3-1029032271.html>. Acesso em: 29.09.2011.

POSTMAN, Neil. O desaparecimento da infância. Trad. Suzana Menescal de A. Carvalho e José Laurenio de Melo. Rio de Janeiro: Grafhia Editorial, 1999.

TROUDE-CHASTENET, Patrick . Ellul l'inclassable. Disponível em: <http://www.ellul.org/es1_m.htm>. Acesso em: 29.09.2011. 
